\title{
The impact of the pandemic on communication between local government and citizens in a small village in Tuscany
}

Manuela Farinosi, Department of Mathematics, Computer Science and Physics, University of Udine, manuela.farinosi@uniud.it

Adriano Cirulli, Department of Mathematics, Computer Science and Physics, University of Udine, adriano.cirulli@uniud.it

Leopoldina Fortunati, Department of Mathematics, Computer Science and Physics, University of Udine, leopoldina.fortunati@uniud.it 


\title{
The impact of the pandemic on communication between local government and citizens in a small village in
}

\author{
Tuscany
}

\begin{abstract}
The COVID-19 pandemic has fostered the increasing use of digitally-mediated communication, which has substituted a large part of the face-to-face encounters, work, political, social, and leisure activities, made impossible during the long period of lockdown. What did this entail in small villages, in respect to both citizens and local government, where face-to-face communication has been more resistant to digital mediation? This study aimed to explore the changes seen in institutional communication, and more generally, in the everyday life of citizens and their relationship with local administrators during the first lockdown in Italy. The context explored was the small-scale local community of Peccioli (Tuscany), a village where face-to face communication usually played a pivotal role in the interaction between local government and citizens. This small village represents a good point of observation to understand whether, in contexts such as this, there has been a change in the balance between different modes of communication similar to that seen in more urban environments.

More specifically, the paper presents the main findings emerging from a study exploring on the one hand, the attitudes and opinions of local administrators regarding institutional communication, and, on the other, the evaluations by citizens of the initiatives and the communication by local government and an analysis of their information behaviors. In the first case, a qualitative approach was used, based on 10 semi-structured interviews with local administrators; in the second case, a quantitative approach was adopted based on a survey conducted with a representative sample of Peccioli's citizens. The main finding of the study revealed the crucial role of word of mouth, thus indicating that, contrary to what is generally believed, not all communication has become automatically digital during COVID-19.
\end{abstract}

Keywords: COVID-19; local government; Institutional communication; media practices; Peccioli.

\section{Introduction}

Over just a few months, the COVID-19 pandemic has brought about years of change (not necessarily positive) in the way in which institutions at all levels interact with citizens. During the first lockdown, citizens moved dramatically toward online channels, and public employees have responded in turn, interacting with them from their home through digital media. Numerous scholars (Agostino et al., 2021) have stressed that the responses to COVID-19 have accelerated the adoption of digital technologies by several years, and that many of these changes may stay even after the pandemic is over. According to Gabryelczyk (2020), public administrations have sped up the digitalization process, putting in place at least temporary solutions, strategies, and practices to respond to the needs of the citizenry more quickly and efficiently. 
The speed with which institutions responded to the emergency translated into the widespread implementation of a series of changes at the organizational level, such as, the increasing migration of assets to the cloud, along with increases in remote working, and the use of advanced technologies in operations. But how have all these changes been experienced on the ground, especially in a small village? Our main hypothesis is that in a small village context, although there is progressive digitalization of communication, both on the side of citizens and on the side of local administrations, face-to-face communication, and therefore more traditional communication tools and strategies, have maintained a crucial role in the pandemic period.

This contribution focuses on Peccioli, a Tuscan municipality of 4649 inhabitants (ISTAT, 2021) (Figure 1), and aims to investigate the changes occurring in public communication and, more generally, in the relationship between citizens and local administrators during the first Italian lockdown in spring 2020.

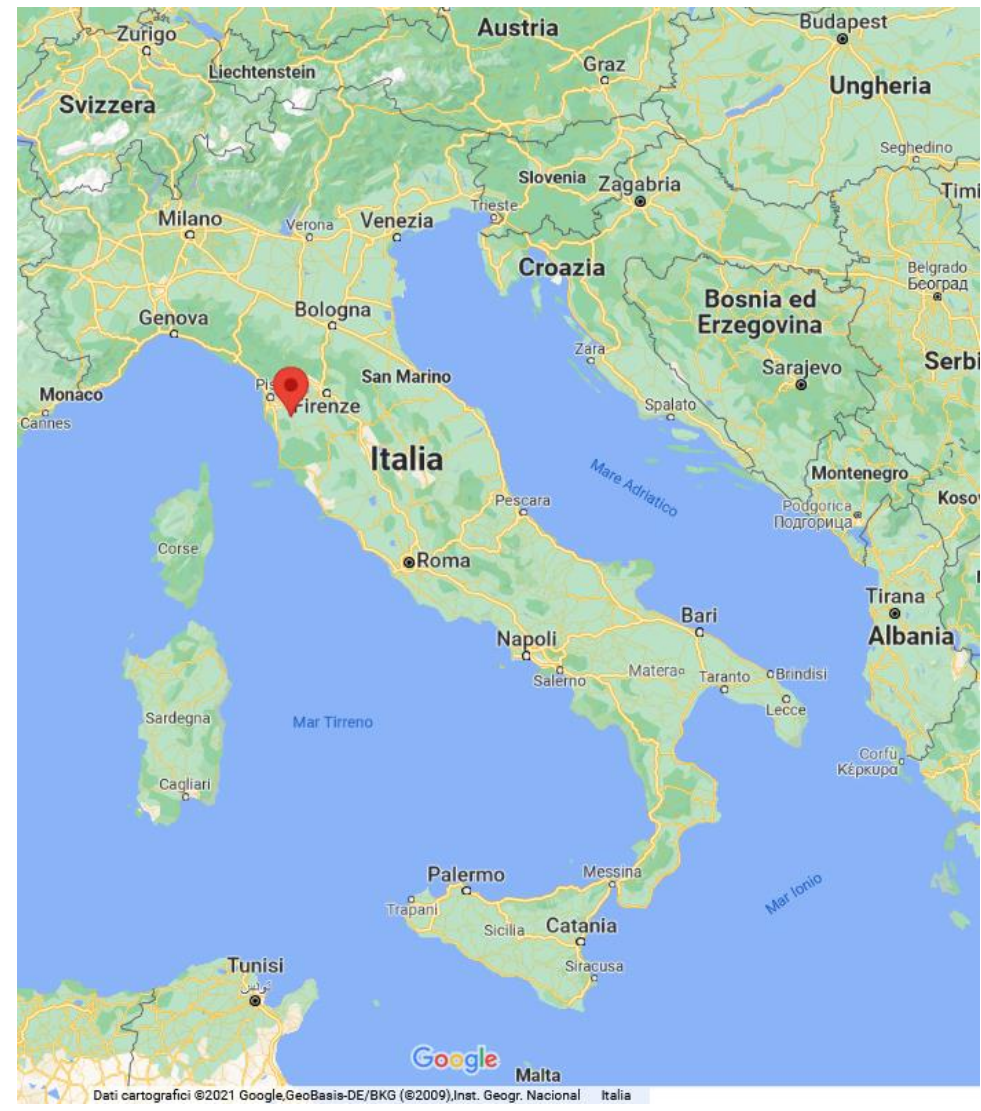

Figure 1: A map showing the location of the village of Peccioli in Tuscany, Italy

Peccioli represents a context in which we could observe that, in ordinary times, face-toface communication plays a central role in citizen-administrator interaction. This small village is an avant-garde municipality, especially when compared to others of similar size in Italy. It is a place with a strong agricultural and touristic vocation: besides having a valuable historical, 
cultural, and environmental heritage, it has been able to enhance its territory in terms of environmental sustainability and quality tourist reception. The territory of the municipality of Peccioli has an area of $92.60 \mathrm{~km}^{2}$ and a population density of 50.20 inhabitants $/ \mathrm{km}^{2}$ (sparsely populated). The population is distributed in a heterogeneous way between the administrative center and the different hamlets that make up the municipality: Cedri (11.72 km from Peccioli), Fabbrica $(6.25 \mathrm{~km})$, Ghizzano $(8.13 \mathrm{~km})$, Legoli $(8.73 \mathrm{~km})$, Libbiano $(6.33 \mathrm{~km})$, Montecchio (3.39 km) and Montelopio (7.24 km; Figure 2)

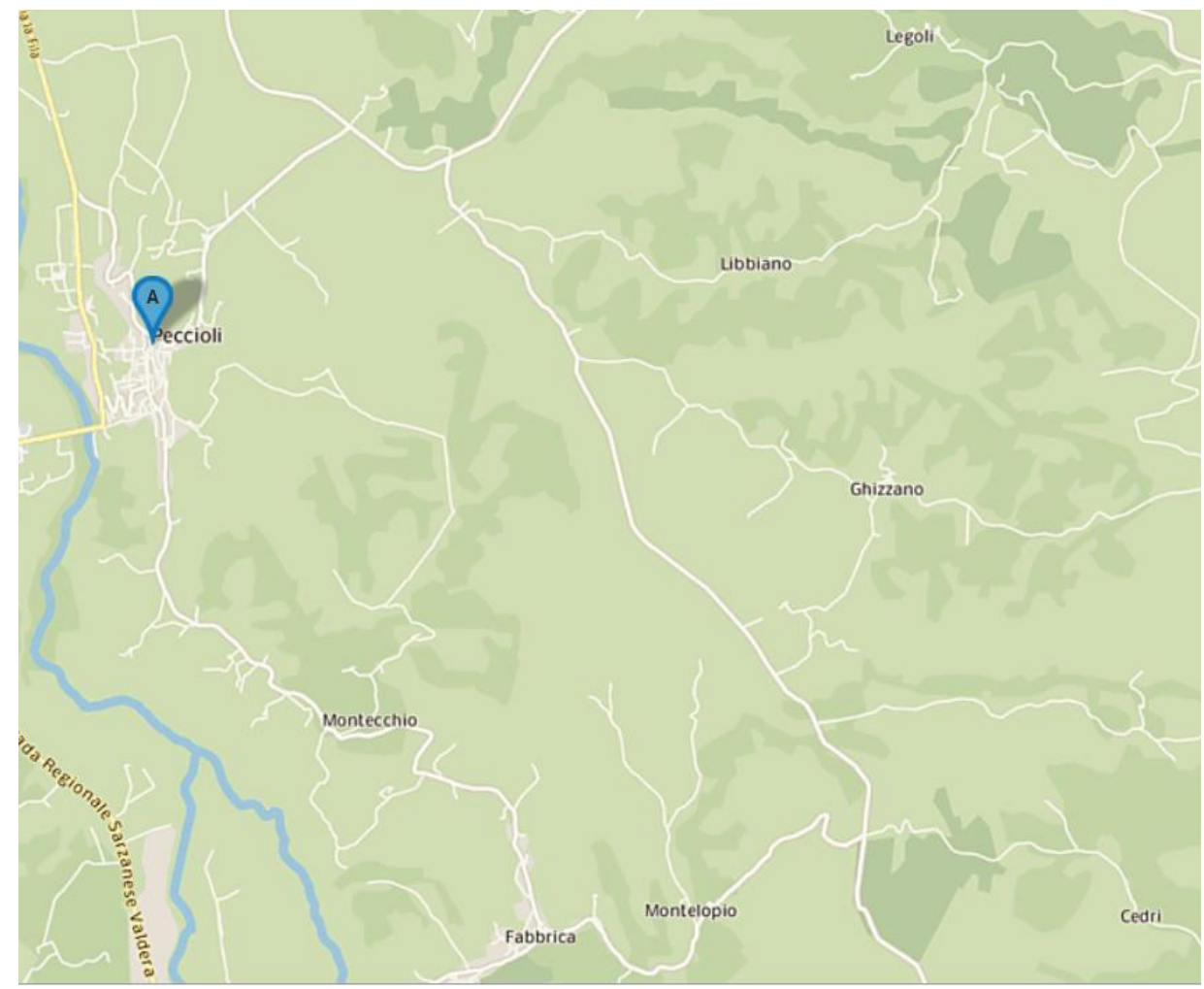

Figure 2: A map of the hamlets of the municipality of Peccioli

Thanks to the policies implemented over the years by the local administration, the investments in infrastructure, the numerous services provided, and the artistic and cultural initiatives that have improved the quality of life of the inhabitants, Peccioli has recently been quoted as an example of a Resilient Community in the Italian pavilion of the 17th Biennale of Architecture 2021 in Venice. The village has, since 1997, made a virtue of necessity applying a resilient logic. When in those years the dominant attitude to landfills and waste was that of NIMBY ("Not in My Back Yard"), Peccioli faced the environmental issue with a PIMBY ("Please in My Back Yard") approach and, by building a territorial and participatory management, gave life to a large waste treatment and disposal plant that over the past two decades has allowed the municipality to develop and invest in sustainability, culture, innovation, architecture, and art. The plant, which is one of the few cases of landfill in the world characterized by the almost total 
absence of conflict at the social level (Caspretti, 2013), is managed by Belvedere, a joint-stock company with mixed public-private capital, where approximately $64 \%$ of the shares are held by the municipality and the remaining $36 \%$ by approximately 900 small shareholders, most of whom reside in Peccioli (Belvedere, 2021). This plant highlights in an emblematic way the existing relationship between citizens and local administrators and represents just one example of the many initiatives promoted by the municipality that involve the broader public in the decisions regarding its territory. Over the last 30 years, numerous civic engagement initiatives and experiences of public consultations have been developed, making the village a sort of open-air laboratory for testing various innovation practices, not only at the social level, but also at the environmental, administrative, and technological levels (Farinosi et al., 2019).

Returning to the purpose of this study, we were interested in exploring on the one hand the attitudes and opinions of local administrators regarding the institutional communication and, on the other, the evaluations of citizens toward the initiatives and the communication of the local government and the analysis of their information behaviors.

In the first case, a qualitative approach was adopted based on 10 semi-structured interviews (Silverman \& Patterson, 2021) with local administrators, aimed at investigating (a) the management of institutional communication and the communication strategies implemented toward the citizenry; and (b) the impact of the pandemic on the organizational and communicative dimension of local government.

In the second case, a quantitative approach was adopted based on the administration of a questionnaire (Corbetta, 2014) to citizens selected randomly on the basis of a representative sampling of the local population $(\mathrm{N}=268)$, aimed at exploring the relationship between citizens and representatives of local institutions, as well as their respective use of the media, both institutional and non-institutional, and the way in which citizens were informed about what had been put in place by the local government.

Specifically, this paper addresses the following research questions:

- RQ1: How did the municipality organize its communication infrastructure and strategy effectively to face the citizens' increasing need for information and the national guidelines established to combat the pandemic?

- RQ2: What was the citizens' evaluation of the public communication during the emergency, and which channels had been mostly used to stay updated on municipal initiatives?

The present article is structured as follows: In the next section, it sets out the theoretical background underpinning our research and provides a literature review regarding public communication during the COVID-19 crisis; Second, it presents the methodology adopted in the study. Third, it describes the main findings, illustrating first what emerged from the interviews with local administrators and then from the survey conducted with citizens and finally discusses these findings and draws some conclusions. 


\section{Public communication, the digital revolution, and the challenge of the COVID-19}

The integration of digital platforms and social media by public administrations in their communication with citizens is a phenomenon that has been developing for several years, responding to the growing relevance of digital media in various realms of our societies (Feeney \& Porumbescu, 2021). For public administrations, this technological innovation has had a broader impact that has also involved their organizational dimension, the definition of the relationship between institutions and citizens and therefore, more generally, the redefinition of democracy itself. In respect to other European countries, Italy in the last 20 years has delayed the process of digitizing public administration and harmonizing its IT infrastructure. Many administrations, especially local ones, are still at an early stage both in the process of acquiring the skills necessary for effective communication through digital media and in the definition of a communication strategy capable of strengthening their social identity (Mori et al., 2021). Moreover, the increasing use of digital media by the public administration runs the well-known risk of excluding from the communication processes those sectors of citizens that do not use new technologies, as well as people with no or low digital competencies (Zheng \& Walsham, 2021).

These delays are also found in social media use. The Italian public administration does not have a formal obligation to use social media to communicate with citizens. The Law 150/2000 establishes that the information and communication activities of public administration can be carried out through any tool that can ensure the transmission of the message. Grounding this important reform in the early 2000s, several Italian public administrations at various levels have begun the increasing their use of digital technologies, in particular social media, as a tool for public communication with citizens, albeit with important critical issues being noted. These criticisms include: the need for more and better training of institutions' press offices more effectively managing these new tools; the frequent overlap, especially in local administrations, between institutional communication - which should remain politically neutral - and political communication; and, finally, the difficulty in developing a proper two-way communication flow (Ducci et al., 2020).

Despite these challenges, social media are important because they have produced a profound transformation of the media ecosystem. Here, a growing process of disintermediation is taking place that on the one hand favors a more direct relationship between public administration and citizens, bypassing traditional media, and on the other hand exposes public administrations to more responsibility and control by citizens than in the past (Delli Carpini, 2020). Moreover, in recent years they have played an increasing role in the management of emergencies and disasters by institutions at different territorial scales (Coombs, 2016). Within this framework, the COVID-19 emergency represented an important accelerating factor in the ongoing process of digitalization of public administration and in the use of social media as a communication tool between administrators and citizens (Gabryelczyk, 2020). Social media have in fact represented a necessary resource to respond to the rapid growth in the demand for information by a fearful population in search of certainty and reassurance. Political and health institutions have also had to be present on social media to counter the spread of fake news concerning the pandemic (Lovari, 2020). 
In addition to all the reasons illustrated so far, there is another reason why it may be particularly relevant to explore how COVID-19 has affected public administration in Italy, since Italy was the first western country to experience the spread of the virus in its territory. Therefore, political and health institutions found themselves dealing with the emergency, and with communication with its citizens, without having the possibility of being inspired by practices already experimented with in other countries. Thus, they had to improvise how to respond to the greater need for information manifested by the Italian population because of the emergency (Carelli \& Vittadini, 2020). To this end there was a significant growth in the presence on social media of health and political institutions, at national and local level (Mazzoleni \& Bracciale, 2021), and, at the same time citizens have also turned their attention mainly to social media (Lovari, 2020).

This change in public and political communication due to the COVID-19 emergency has had a strong impact on the transformation of political leadership in Italy, as in other countries (Ansell et al.,2020; Lilleker et al., 2021). Firstly, the increased use of social media and disintermediated communication by political leaders and holders of government responsibilities, at local as well as at national level, has sharpened the process of personalization of political leadership that in the last decades has characterized the political systems in all western democracies, including Italy. During the different stages of the pandemic crisis, the Italian PM Giuseppe Conte, as well as the Presidents of the Regions (which in Italy have competencies for the management of the Public Health System), and the mayors of cities of different territorial scales, had been personally engaged in direct communication with citizens, particularly on social media platforms. Political leaders, through an effective storytelling, appeared as "captains in the storm", able to capture the support of public opinion, so strengthening their leaderships (Ventura, 2020).

Secondly, due to the direct involvement of experts in public communication regarding the pandemic and the measures to follow its containment - such as epidemiologists, physicians, etc. - in Italy also emerged a sort of depoliticization of leaders' communication. Political leaders were careful to ground their message on the opinion of experts, trying to avoid expressing a partisan and politically oriented view on the crisis. Nonetheless, the different views on the emergency and its management that also characterized the debate between scientific experts, eventually increased the levels of confusion in the communication pursued by Italian political institutions through their leaders (Castellin \& Palano, 2020).

Several scholars consider the response of institutional and media actors to the increased information need of the citizens to be at least partially ineffective and inadequate. According to Centorrino (2020), alongside the infodemic (Yang et al., 2021; Brennen et al., 2020; Zarocostas, 2020) a comdemic also took place, that is, an overabundance of actors who wanted to be accredited in the field of public institutional communication. A scenario of uncertainty and confusion that "gave rise to a cacophony of voices, in which institutional communication was often misaligned with media coverage and with an indistinguishable mix of misinformation, unverified rumors and intentionally manipulated disinformation" (Lovari, 2020, p. 459).

With regards to local administration, the specific subject of this contribution, a recent study (Mori et al., 2021) has shown that even at the level of municipalities, in the first months of 
the COVID-19 emergency there was a notable increase in the presence of local administrations on social media; an increased presence that received a positive response from the population, as evidenced by a general and dramatic growth of citizens' interactions with the social media pages and profiles of municipal institutions. According to the authors of the study:

The increased number of citizens interested in remaining connected and up-to-date with these institutions reveals that public administration is one of the actors of communication considered affordable by citizens. From the perspective of user/consumer behavior, it is interesting to observe that the rise in the number of fans is continuous in the period analyzed for all municipalities and this confirms the importance of the digital communication channels in bringing citizens closer to the public administration. The sharp and sudden rise seems to confirm that users were already digital consumer, not yet used to virtually interact with the public administration (before the pandemic, the number of fans of all the municipalities investigated was low), but immediately reactive, if necessary, as in a context of emergency. (Mori et al., 2021, p. 11).

However, this possible positive impact of the COVID-19 emergency on the innovation of public communication by local administrations and on citizens' involvement has been partially accompanied by the persistence of some of the challenges and limitations that had characterized the use of social media by Italian public administrations since its early stages, before the COVID19 crisis. Among the main ones are that often, during an emergency, local institutions have used social platforms without having specific skills and without a complete knowledge of their potential, especially in terms of interactions between government and citizens. From this perspective, an emergency can certainly be interpreted as a period of experimentation, learning and transition from a traditionally one-way, informative communication, to a communication characterized by a greater degree of interaction.

For a better understanding of the impact of the COVID-19 emergency on public communication by local administrations, as well as of the relationship between their new and traditional communication strategies, it is necessary also to consider the scale dimension, since urban and rural contexts represent completely different situations. In this paper, we try to shed light on what happened in a small village environment.

\section{Aims and methods}

Our work intended to analyze the case of the municipality of Peccioli. In order to answer our research questions, this study adopted the following tools: 1) semi-structured interviews with local administrators to explore their point of view on the management of public communication and information strategies and to investigate the impact of the pandemic on the organizational dimension of the local administration; and 2) a survey carried out with a representative sample of Peccioli's population to investigate citizens' evaluation of the local government's communication with the population during the COVID-19 crisis and eventual changes in citizens' use of media. 
As for the interviews with local administrators, a total of 10 semi-structured interviews (Silverman \& Patterson, 2021) were conducted at the municipality headquarters in May 2021, concerning institutional communication strategies used by the municipality during the first Italian lockdown. Among the administrators we decided to include in the sample institutional figures covering different roles: mayor, deputy mayor, council members, communication managers, etc. The profile of those interviewed was rather heterogeneous, in terms of both age (ranging from 31 to 71 years) and gender (five women and five men). The qualitative approach allowed us to focus more on the depth of the discourse and capture in detail the experiences and opinions of the respondents through their own words (Vettehen et al., 1996). In addition, given the exploratory nature of the research, the semi-structured interview seemed the most appropriate in terms of openness and flexibility, providing the freedom, where necessary, to expand the questions and ask for further clarification. The interviews lasted between 25 and 80 minutes and were conducted by meeting in person - by appointment - with local administrators. All interviews were audio-recorded, transcribed in full and subjected to a first reading to identify interviewees' subjective perceptions and points of view, capture the overall meaning of their discourse, highlight salient passages, and find any inconsistencies, and, subsequently, to carry out a closer analysis in order to achieve a systematization of the material (Braun \& Clarke, 2008; Guest et al., 2012). Specifically, the textual corpus resulting from the interviews was processed following an inductive procedure aimed at identifying the most relevant and significant thematic categories (Boyatzis, 1998; Ryan \& Bernard, 2003) and then at expanding and enriching the initial list by adding categories and subcategories that were maybe less frequent but still important. The interview excerpts were then reorganized according to these categories and analyzed crosswise.

As for the survey conducted with citizens, a probabilistic stratified sampling approach was applied to draw a representative number of inhabitants of Peccioli by randomly extracting participants from the municipal registry through proportional allocation based on three sociodemographic variables: age, consisting of five groups - adolescents (14-18 years), young people (19-24 years), young adults (25-44 years), adults (45-64 years) and elderly (over 64 years); gender (male/female); and place of residence (center/hamlets). In order to improve the survey response rates, representativeness, and to ensure sufficient data for decision-making, after determining the sample size $(\mathrm{N}=356)$, we decided to double it and then include an additional 100 people. A total of 812 citizens were invited to participate in the research through an invitation letter signed by the mayor of the town and hand-delivered by a municipal messenger. In the end, 268 people were interviewed, resulting in a response rate of $72.5 \%$ compared to the original sample size. Despite our efforts, the final sample suffered, not surprisingly, from some self-exclusion mechanisms, presenting representation bias attributable mainly to a low response by adolescents and youths and a higher participation of women than men. However, despite this limitation, the response rates reached some good levels. The sample was made up of 114 males (42.5\%) and 154 females (57.5\%). Regarding the age of respondents, 11 (4.1\%) were adolescents, 10 (3.7\%) young people, 54 (20.1\%) young adults, $106(39.6 \%)$ adults, and 87 (32.5\%) elderly. Regarding the place of residence of respondents, 165 (61.6\%) lived in Peccioli and 103 (38.4\%) in nearby hamlets (Cedri, Fabbrica, Ghizzano, Legoli, Libbiano, and Montecchio). 
Given the confinement and social distancing measures imposed by the government to contain the COVID-19 pandemic, data were collected using structured questionnaires administered through mobile phone interviews (Boase \& Humphreys, 2018) during the period from 7 July to 20 October 2020, and through in-person interviews from September 2020, following the relaxation of virus restrictions. The questionnaire consisted mainly of closed questions covering four thematic blocks: 1) basic sociodemographic characteristics of the respondent (e.g., age, gender, education, marital status, employment, household, etc.); 2) evaluation of the initiatives undertaken by the local government to deal with the emergency, grouped into four areas (i.e., supply of personal protective equipment such as masks, services to citizens, support for recreational and cultural activities, and allocation of funds for the poorest and most distressed citizens); 3) information channels used to stay up-to-date on initiatives promoted by the municipality and evaluation of institutional communication during the lockdown; and 4) suggestions on how to improve COVID-19 emergency management in the event of a possible second wave of the virus (this last block was the only one that consisted only of open-ended questions). In relation to the second thematic block, to overcome the problem of uninformed citizen input we considered it appropriate to first provide respondents with detailed information about the initiatives promoted by the municipal administration so that they could start from a common knowledge base before expressing their evaluation (Bolles, 2013; Farinosi et al., 2019).

Given the specific focus of this contribution and the richness of the data collected during the survey, our report here is confined exclusively to the analysis of the responses related to the questions concerning institutional communication and to those that made up the third thematic block of the questionnaire. This analysis was performed using SPSS software, version 23.0.

\section{Findings}

The findings have been organized in the following way: in the first sub-section the most relevant results from the analysis of the interviews with the local administrators will be illustrated, accompanied by some significant excerpts taken directly from the words of the respondents; in the second sub-section the main data from the survey conducted with a representative sample of the population of Peccioli will be presented.

\section{Interviews with local administrators}

Regarding the issue of the eventual changes emerging in the public communication and communication strategies developed by the Peccioli municipal government during the pandemic, from the interviews it emerged that this municipality did not modify its communication infrastructure to inform citizens during the various phases of the emergency. The municipality continued to use its institutional channels, avoiding the use of social media: 
The Administration has informed and communicated every activity, perhaps preferring more traditional channels (institutional website and press releases to local media) and the smartphone app 'Sistema Peccioli' (Anna Dainelli, Deputy Mayor).

A crucial choice regarding the communication strategy was to not provide, through social media platforms, a daily bulletin of cases of infections, hospitalizations, and deaths, related to the territory of the municipality of Peccioli. Contrary to what happened in neighboring municipalities, the Mayor of Peccioli decided to not provide this type of information because, given the context and the small size of the community, he determined that a daily bulletin concerning cases could facilitate the spread of panic and a dangerous "witch hunt" scenario:

Compared to others who have communicated three times a day the data that 'there is one more infected, there are two more infected', creating a kind of continuous and constant tension, we preferred to leave the task to the ASL [Local Public Health institution] that communicated the provincial data every day. In a small reality like this one, informing that in Via Roma there was one positive case of COVID, is nonsense. It would have meant creating dangerous situations. On the contrary, since the moment someone was identified as infected, the first to know about it were the health workers; at that point the necessary and sufficient countermeasures were taken to make everyone feel safe (Renzo Macelloni, Mayor).

At a general level, some studies carried out in recent months have shown how local administrators, and particularly mayors, have become the main storytellers of the crisis, the interpreters of the so-called "proximity policies", which is the political subjectivity aimed at strengthening the value of solidarity in local communities (Sampugnaro \& Santoro, 2021). In Peccioli, the municipal administration, and the figure of mayor chose to play this role more through the implementation of initiatives and interventions than through a constant and daily presence on the various media platforms.

However, some of the interviewees registered discontent among certain sectors of the population who, especially in the first periods of the emergency, would have preferred to receive detailed and daily information on the local COVID-19-positive cases. Due to this experience, the municipality decided to pay more attention to their presence and communication on social media platforms, while maintaining an institutional profile that tried to avoid the dynamics of polarization that are often found on social media platforms:

I know that many citizens, in line with the general and growing habit of using social networks as a source of information, would like a greater presence of the Administration on platforms such as Facebook and Instagram. I think we should work on this and structure ourselves better, still maintaining an institutional profile and style. We should use and monitor these channels that have now become an integral part, not just of our way of communicating, but also of our way of behaving (Anna Dainelli, Deputy Mayor).

As recounted by various interviewees, the decision to start taking advantage more effectively of the communication through social media platforms had already been made before the beginning of the COVID-19 emergency, with the creation of an official Facebook profile of the 
municipality and the hiring of a professional dedicated to this type of communication within the press office. However, the increase in remote interaction and the greater presence of citizens on social media platforms during the COVID-19 emergency has already reshaped the municipality's communication infrastructure:

Recently, an official Facebook page of the municipality was created. So, now we communicate also through this channel. [...] The Facebook page wasn't created for the emergency. We have been thinking about it for a while till recently, but it wasn't created just for the COVID emergency (Isabella Volpi, Mayor's Staff).

We have noticed that some things have actually improved in terms of usability. I think, for example, about what we did in preparation for Venice [the participation at the Biennale Exhibition]. We started, as Belvedere, to reshape our webpage. Then, we have dedicated ourselves to create a specific website on tourism which will be online soon. That is, we are a little more focused on improving certain tools that allow us to communicate better even outside. For example, the municipality of Peccioli is employing a person who will oversee the press office, also taking care of the communication through social media. I think this aspect will be treated and managed more carefully, still maintaining an institutional profile (Arianna Merlini, Belvedere Spa).

Despite this recent attention to online communication channels, however, given the specificities of the context of Peccioli (such as the presence of an important component of the elderly population that is difficult to "digitize", and the small size of the community), direct faceto-face communication between citizens and civil servants and administrators remains crucial:

The average citizen wants to see the real person; she/he doesn't trust these instruments. It is useless [to focus too much on digitalization], also because our population is quite old (Maurizio Salvini, Municipal Secretary).

We're a small reality here. So we all catch up [...] you either come to the City Hall or you post a problem on social media, and I know immediately if there is a problem. I mean the reality, in a small municipality like this, is completely different compared to bigger cities (Renzo Macelloni, Mayor).

During the pandemic, the municipality has registered an increase in contacts with citizens even if, due to the measures taken for virus containment, it has not produced an increase in the physical presence of citizens in the municipal offices. Rather, there was an increase in contacts via telephone and email and, especially in the case of the younger citizens, through the smartphone app "Sistema Peccioli".

\section{Citizen Survey}

In this section, we present the results that emerged from the survey conducted with citizens, focusing on those relating to the section of the questionnaire concerning communication. Before exploring their perception of the institutional communication, it is worth illustrating the channels normally used by the citizens of Peccioli to stay informed during the pandemic and their media 
usage compared to the pre-emergency COVID-19 phase. The analysis of the results reveals that the most used device was the television (50.0\%), followed by mobile phones ( $27.6 \%)$, computers $(17.5 \%)$, newspapers $(3.0 \%)$, and radio (1.5\%); the remaining $0.4 \%$ of respondents stated that they had not used any medium. These data highlight how the interviewees' media usage was characterized by a high prevalence of traditional media over the new ones. Moreover, the large majority of respondents (79.5\%) declared to have used more interpersonal communication tools, especially to keep in touch with friends and relatives, and to have kept themselves more informed than in ordinary times (70.9\%). A little more than half stated that they used more social media platforms (Facebook, Instagram, etc.), and watched more TV (in the two cases the percentage was the same: $55.2 \%)$, while a third watched more streaming content (32.5\%) and a fifth shopped more online (22.0\%). Thus, it is worth noting how the advent of the pandemic and, above all, the imposition of confinement measures has led to an increase in all the communication activities considered by our questionnaire, including those online. This relevant increase in communication activities is also accompanied by other meaningful scientific evidence arising from the specific modality of the answers we proposed. Among the possible answers to this question, in addition to the traditional options "the activity has increased", "the activity has decreased" and "the activity has remained unchanged compared to before the pandemic", we had also provided the option "I have never done this activity". Significantly, 34.0\% of respondents said they had never used social media platforms, $49.3 \%$ had never seen streaming content and $43.7 \%$ had never done online shopping, neither before nor during the emergency. These data demonstrate a certain resistance on the part of the local community to using digital media and adopting the most innovative communication channels, which must be kept in mind for a more complete reading of the data concerning institutional communication in such a small village.

Overall, the answers provided by the interviewees to the questions focusing on this issue revealed that they adopted a mixed regime of analog and digital media, strongly characterized by a preponderance of the analog. The most used communication channel through which citizens of our sample became aware of the various initiatives and services activated by the municipal administration was word of mouth, followed by social media platforms and then the municipality's official app (Figure 3). It should be emphasized that it is possible to detect a direct correlation between the most used means of communication and the type of initiative promoted by the municipal administration. In general, word of mouth was the most used across all the initiatives investigated, except for the festival "Pensavo Peccioli" ("I thought Peccioli"). This cultural event, renamed "Cosa sarà?" ("What will be?"), in which popular journalists well known at the national level publicly discuss current affairs, had been rethought in online mode to follow the measures to combat the spread of the virus. In this case, the citizens interviewed declared that they became aware of the initiative mainly through online platforms. 


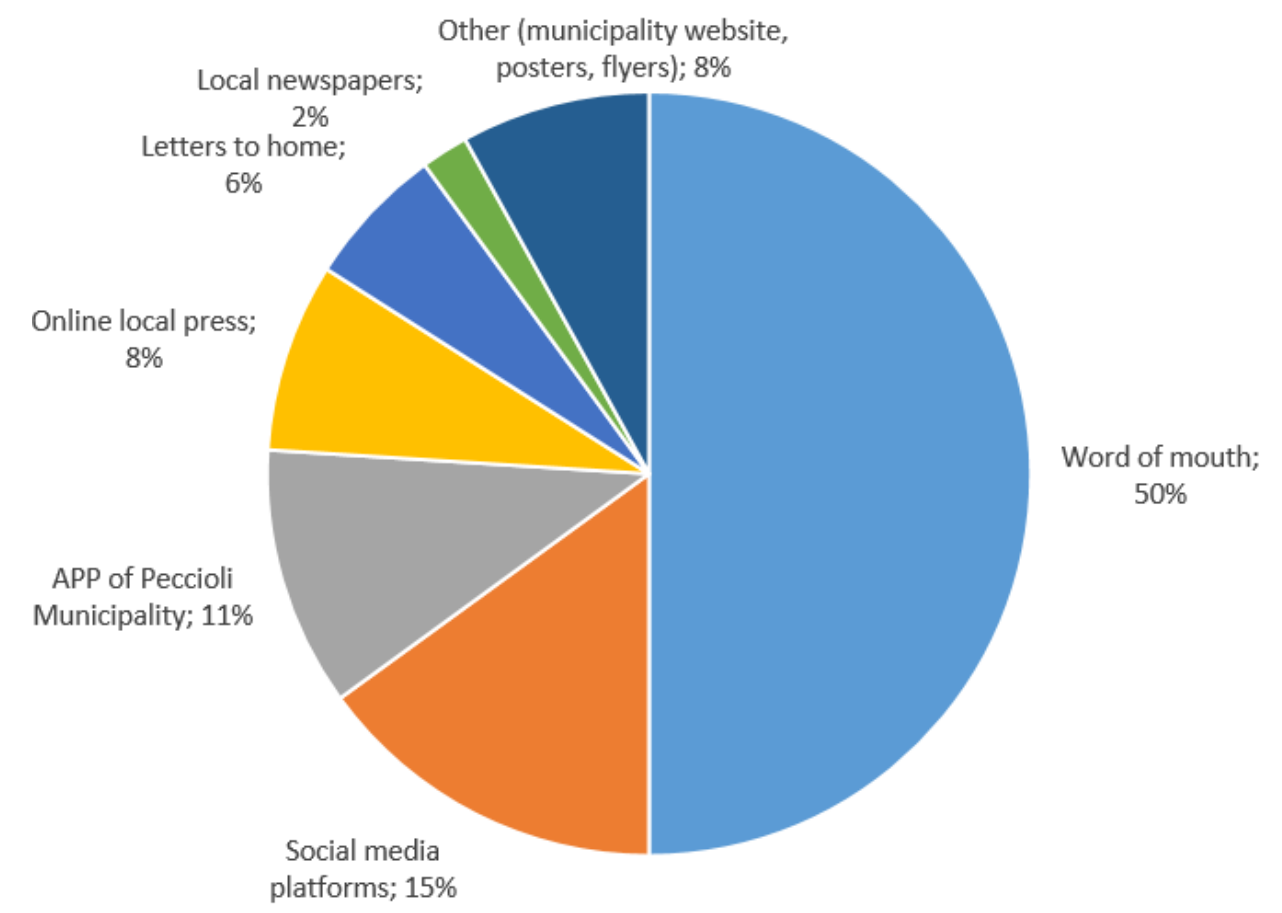

Figure 3: Information channels most used by citizens to stay updated on the initiatives promoted by the municipality. Source: Farinosi and Piccolo (2021).

Looking more closely at the four areas in which the initiatives undertaken by the local government have been grouped: 1) supply of personal protective equipment; 2) services to citizens; 3) support for recreational and cultural activities; and 4) allocation of funds for the poorest and most distressed citizens, we notice that, in regards to the actions in the first area, citizens have learned about it mainly through word of mouth (41.4\%), followed by "other" $(22.4 \%)$ and social media platforms $(13.1 \%)^{1}$. In particular, the specific case of the distribution of protective masks to citizens, the item "other" reached a rather high percentage because people often reported having learned about the initiative directly by finding the masks in their mailbox.

As regards initiatives related to the second area, the respondents stated that they were informed mainly by word of mouth $(57.8 \%)$, followed by social media platforms $(15.0 \%)$ and by local online newspapers (8.8\%). In this case, it is possible to detect a difference related to the specific type of service considered: for example, the home delivery service for shopping and medicines was better known through word of mouth and online platforms, while the existence of the service of psychological support via telephone was learned of mostly through local online newspapers.

Considering the initiatives related to the third area, the respondents replied that they had become aware of them through word of mouth (35.6\%), social media platforms $(26.1 \%)$ and the

${ }^{1}$ We report here only the three options that received the most responses, with the relative percentages. 
municipality app (19.3\%). In this case, the answers were distributed in a more homogeneous way and, as anticipated, the reasons can be tracked down to the very nature of these initiatives; in fact the "Pensavo Peccioli" festival was only available online and two proposals required a reservation through the municipality app to access.

Finally, in regards to the initiatives covering the fourth area, respondents said they learned about them mainly through word of mouth $(55.1 \%)$, followed by online newspapers $(11.0 \%)$ and online platforms $(9.0 \%)$. In this case, beyond the three most used channels, there was a higher variability in the answers according to the specific initiative being evaluated. Paper letters, sent to homes by the municipality and delivered by municipal messengers, supported the dissemination of information regarding the advance payment of the Belvedere social dividend to shareholders and the contribution to support youth training. This probably happened because the people directly affected by these measures were already involved in the initiatives. The municipality app, on the other hand, proved useful in promoting the initiative of providing shopping vouchers to support citizens with low incomes and, finally, the meetings with administrators served to spread greater knowledge of the modification of the budget implemented in the face of the emergency.

In general, the interviewees rated the emergency management implemented by the municipal administration very positively, giving it a rating of 4.39 on a scale of 1 to 5 (SD $=0.807$ ). The few negative evaluations could be traced back to two types of reason: lack of attention to specific segments of the population (i.e., children and elderly) and lack of support for some working sectors, such as tourism, which was hit hard by the COVID-19 crisis. Institutional communication during the lockdown was also assessed positively by the respondents, receiving a score of 3.72 (SD =0.965). The Kendall rank correlation coefficient $(r=0.431, p<0.001)$ also demonstrates that there is a moderate, even if significant, correlation between these two items: as appreciation for the work of local government increases, appreciation for institutional communication also grows. In relation to sociodemographic variables, we note that men expressed a positive evaluation (equal to 4 or higher) of institutional communication more often than did women. Respondents belonging to the category "young people" (19-24 years) expressed a rating of 4 or higher more often than the other age groups, while the category "adolescents" (14-18 years) expressed it less frequently. Finally, the respondents residing in Peccioli more often provided a positive evaluation than those residing in the hamlets.

According to the respondents, the information channel considered most effective among those used by the municipality during the pandemic was letters sent to homes, followed by the official municipality app (Figure 4). All the other response options, as can be seen from the graph in Figure 4, received scores equal to or lower than $10 \%$. However, it is interesting to underline that some respondents answered this question by indicating the local online press and the Facebook group "Sei di Peccioli se..." to be the most effective institutional means of communication, two channels which, due to their characteristics, do not fall within the definition of "institutional means of communication" and are not directly managed by the local administration. 


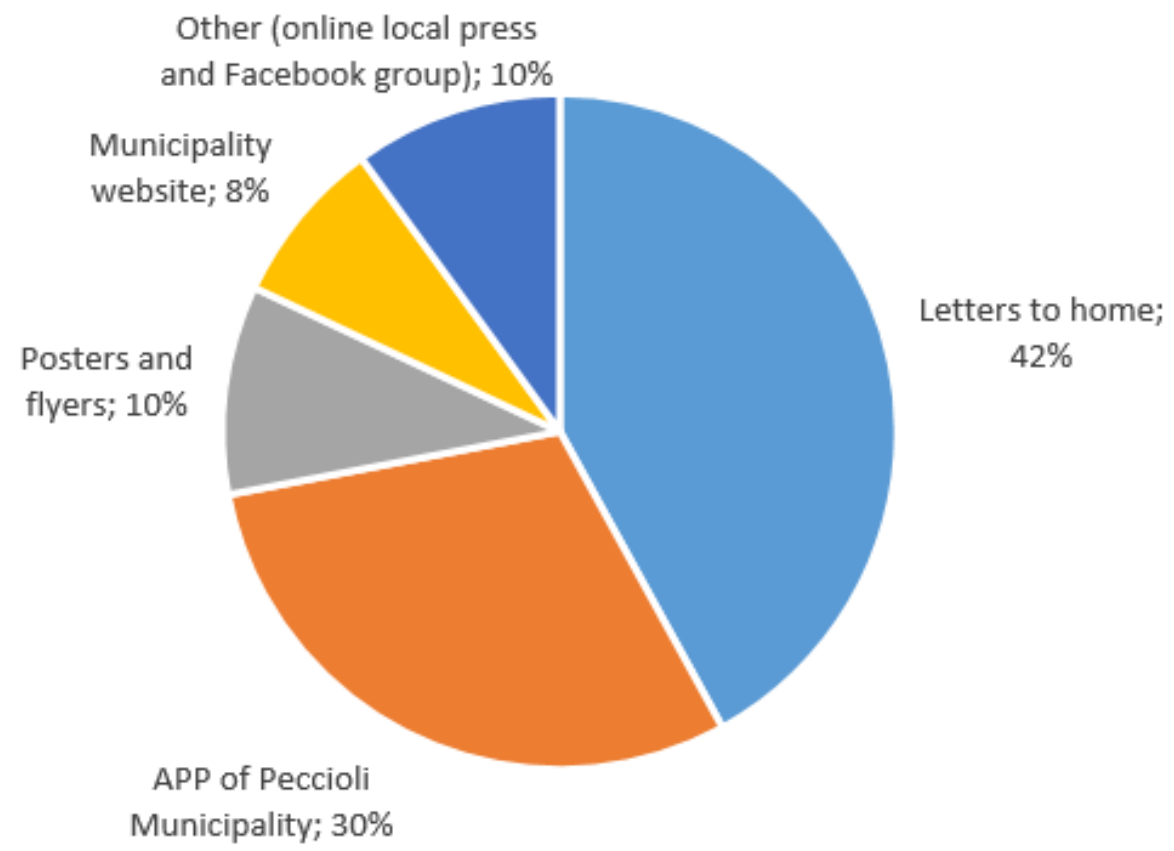

Figure 4: Institutional channels considered most effective by citizens. Source: Farinosi and Piccolo (2021).

\section{Conclusion}

Among the various effects of the COVID-19 pandemic at the communication level, our study has identified, on the one hand, an increase in communication practices by citizens and an increase in the use of both analog and digital media and, on the other, a moderate increase in the process of digitalization of public communication and the initial use by public administrations of social media as a tool for communicating with citizens.

The insights provided by the case of Peccioli show us how, even in this small town, the pandemic has represented a factor of pressure toward the digitalization of public communication. The administration of the municipality, in fact, also in light of the experience of the first months of the pandemic, had decided to reshape and strengthen its communication strategy by integrating social media into its communication infrastructure; a choice that, as expressed by the administrators interviewed, had been postponed given the well-known risks of undesirable effects in local government (such as polarization, the spread of panic in emergency situations, widening the digital divide, etc.). At the same time, the citizens of Peccioli, while acknowledging that they experienced a greater use of digital and social media during the period of the first lockdown, and while also requesting a greater presence on social media by the municipal administration, still consider traditional channels of communication to be the most relevant. According to the data collected through the survey, word of mouth emerged clearly as 
the most used source to gain information about the initiatives of the municipality. Therefore, in the context of Peccioli, even in a phase of forced distancing and in addition to the growth in digital communication, the role of direct interpersonal communication, even with administrators, remained central, as did the roles of the family, neighborhood, peer group and acquaintances as direct sources of information considered reliable.

These results contribute to an outline of the actual picture of public communication in Italy, considering the social, administrative and geographical relevance of smaller municipalities in this country (De Rossi, 2018). What emerged in Peccioli is most likely to be similar to the situation experienced by many other small Italian municipalities. The characteristics of smaller local administrations, such as the greater presence of an elderly population or one with poor digital competencies, and the relevance of face-to-face communication which, in these contexts, is not completely replaced by digital communication, indicate a different scenario of development of the digitalization of public administration compared to larger municipalities. A greater knowledge of these specificities in the dynamics of local communication in small towns and villages becomes essential, therefore, to identify, through comparative studies, which models and tools can be adopted in different contexts by local administrations to achieve effective public communication in rural and urban contexts.

\section{References}

Agostino, D., Arnaboldi, M., \& Diaz Lema, M. (2021). New development: COVID-19 as an accelerator of digital transformation in public service delivery. Public Money \& Management, 41(1), 69-72. https://doi.org/10.1080/09540962.2020.1764206.

Ansell, C., Sørensen, E., \& Torfing, J. (2021). The COVID-19 pandemic as a game changer for public administration and leadership? The need for robust governance responses to turbulent problems. Public Management Review, 23(7), 949-960. https://doi.org/10.1080/14719037.2020.1820272.

Belvedere (2021). Azienda: Belvedere Spa: progetti, sviluppo, innovazione. https://belvedere.peccioli.net/azienda/.

Bolles, R. N. (2013). What color is your parachute? A practical manual for job-hunters and careerchangers. Crown Publishing.

Boase, J., \& Humphreys, L. (2018). Mobile methods: Explorations, innovations, and reflections. Mobile Media \& Communication, 6(2), 153-162. https://doi.org/10.1177/2050157918764215.

Boyatzis, R.E. (1998). Transforming qualitative information: Thematic analysis and code development. Sage.

Braun, V., \& Clarke, V. (2008). Using thematic analysis in psychology. Qualitative Research in Psychology, $3(2)$, 77-101. https://www.tandfonline.com/doi/abs/10.1191/1478088706qp063oa. 
Brennen, J.S, Simon, F., Howard, P.N., \& Nielsen, R. K. (2020, April 7). Types, sources, and claims of COVID-19 misinformation. https://reutersinstitute.politics.ox.ac.uk/types-sourcesand-claims-covid-19-misinformation.

Caspretti, S. (2013). La strategia del consenso nel caso della discarica di Peccioli [The strategy of consensus in the case of the Peccioli landfill]. Partecipazione e Conflitto, 6(1), 102-120. https://www.francoangeli.it/riviste/Scheda_rivista.aspx?IDArticolo=47942.

Carelli, P., \& Vittadini, N. (2020). Social-virus. Piattaforme, istituzioni e hashtag durante la pandemia [Social Virus. Platforms, institutions and hashtags during the pandemic]. In M. Sala \& M. Scaglioni (Eds.), L'altro virus. Comunicazione e disinformazione al tempo del COVID-19 (pp. 31-51). Vita e Pensiero.

Castellin, L.G., \& Palano, D. (2020). I leader e la paura: la comunicazione politica nei giorni del contagio [Leaders and fear: political communication in the days of contagion]. In M. Sala \& M. Scaglioni (Eds.), L'altro virus. Comunicazione e disinformazione al tempo del COVID19 (pp. 53-61). Vita e Pensiero.

Centorrino, M. (2020). Infodemia e comdemia: la comunicazione istituzionale e la sfida del COVID-19 [Infodemic and comdemic: institutional communication and the challenge of the COVID-19]. Humanities, 9(2), 1-18. https://doi.org/10.6092/2240-7715/2020.2.1-18

Coombs, W. T. (2016). Digital naturals and the effects of social media on disaster communication. In S. Jayakumar (Ed.), State, society and national security (pp. 83-192). World Scientific. https://doi.org/10.1142/10047.

Corbetta, P. (2014). Metodologie e tecniche della ricerca sociale [Social research methods and techniques]. II Mulino.

Delli Carpini, M. X. (2020). Public Sector Communication and Democracy. In V. Luoma-aho \& M.J. Canel (Eds.), The Handbook of Public Sector Communication (pp. 31-44). Wiley-Blackwell.

De Rossi, A. (Ed.). (2018). Riabitare I'Italia. Le aree interne tra abbandoni e riconquiste [Re-living Italy. Inland areas between abandonment and reconquest]. Donzelli.

Ducci, G., Materassi, L., \& Solito, L. (2020). Re-Connecting Scholars' Voices. An historical review of public communication in Italy and new challenges in the open government framework. Partecipazione e Conflitto, 13(2), 1062-1084. http://sibaese.unisalento.it/index.php/paco/article/view/22502.

Farinosi M., \& Piccolo, C. (2021). Public communication and pandemic crisis: The case of the Municipality of Peccioli. Sociologia della Comunicazione, 61, 159-168. http://digital.casalini.it/10.3280/SC2021-061011

Farinosi M., Fortunati L., O’Sullivan J., \& Pagani, L. (2019). Enhancing classical methodological tools to foster participatory dimensions in local urban planning. Cities, 88, 235-242. https://doi.org/10.1016/j.cities.2018.11.003. 
Feeney, M.K., \& Porumbescu, G. (2021). The Limits of Social Media for Public Administration Research and Practice. Public Administration Review, 81(4), 787-792. https://doi.org/10.1111/puar.13276.

Gabryelczyk, R. (2020). Has COVID-19 Accelerated Digital Transformation? Initial Lessons Learned for Public Administrations. Information Systems Management, 37(4), 303-309. https://doi.org/10.1080/10580530.2020.1820633.

Guest, G., MacQueen, K.M., \& Namey, E.E. (2012). Applied Thematic Analysis. Sage. https://www.doi.org/10.4135/9781483384436.

ISTAT (2021). GeoDemo. http://demo.istat.it/popres/index2.php?anno=2021\&lingua=ita.

Lilleker, D., Coman, I., Gregor, M., \& Novelli, E. (2021). Political communication and COVID-19: Governance and rhetoric in global comparative perspective. In D. Lilleker, I. Coman, M. Gregor \& E. Novelli (Eds.), Political Communication and COVID-19. Governance and Rethoric in Times of Crisis (pp. 333-350). Routledge. https://doi.org/10.4324/9781003120254.

Lovari, A. (2020). Spreading (Dis)trust: COVID-19 misinformation and government. Media and Communication, 8(2), 458-461. https://doi.org/10.17645/mac.v8i2.3219.

Mazzoleni, G., \& Bracciale, R. (2021). The Italian Prime Minister as a Captain in the Storm: The Pandemic as an Opportunity to Build Personalized Political Leadership. In P. Van Aelst \& J. Blumler (Eds.), Political Communication in the Time of Coronavirus (pp. 65-79). Routledge. https://doi.org/10.4324/9781003170051.

Mori, E., Barabaschi, B., Cantoni, F., \& Virtuani, R. (2021). Local governments' communication through Facebook. Evidences from COVID-19 pandemic in Italy. Journal of Public Affairs, 21(4), Article e2551. https://doi.org/10.1002/pa.2551.

Ryan, G.W., \& Bernard, H.R. (2003). Techniques to identify themes. Field Methods, 15(1), 85-109. https://doi.org/10.1177\%2F1525822X02239569.

Sampugnaro, R., \& Santoro, P. (2021). The Pandemic Crisis, Italian Municipalities, and Community Resilience. Partecipazione e Conflitto, 14(1), 283-301. http://sibaese.unisalento.it/index.php/paco/article/view/24026.

Silverman, R.M., \& Patterson, K.L. (2021). Qualitative Research Methods for Community Development. Routledge. https://doi.org/10.4324/9781315797762.

Ventura, S. (2020). La pandemia e la crisi della leadership: come il COVID-19 può cambiare la democrazia [Pandemic and the leadership crisis: how COVID-19 can change democracy]. In A. Campi (Ed.), Dopo. come la pandemia può cambiare la politica, l'economia, la comunicazione e le relazioni internazionali (pp. 49-58). Rubbettino.

Vettehen, P.H., Renckstorf, K., \& Wester, F. (1996). Media use as social action: Methodological issues. In K. Renckstorf, D. McQuail, \& N. Jankowski, (Eds.), Media Use as Social Action (pp. 32-42). Libbey. 
Yang, K., Pierri, F., \& Hui, P. (2021). The COVID-19 Infodemic: Twitter versus Facebook. Big Data \& Society, 8(1), 1-16. https://doi.org/10.1177/20539517211013861.

Zarocostas, J. (2020). How to fight an infodemic. The Lancet: World report, 395(10225), 676. https://doi.org/10.1016/S0140-6736(20)30461-X.

Zheng, Y., \& Walsham, G. (2021). Inequality of What? An Intersectional Approach to Digital Inequality under COVID-19, Information and Organization, 31(1), Article 100341. https://doi.org/10.1016/j.infoandorg.2021.100341. 